\title{
Thermodynamic Properties of Polyethylene Predicted from Paraffin Data
}

\author{
Martin G. Broadhurst
}

(February 13, 1963)

\begin{abstract}
Thermodynamic data on the $n$-paraffins from $n-\mathrm{C}_{6} \mathrm{H}_{14}$ through $n-\mathrm{C}_{18} \mathrm{H}_{38}$ have been used to obtain values for the specific heat, entropy, enthalpy, and Gibbs free energy of a large, ideal $\mathrm{CH}_{2}$-chain crystal from 0 to $420^{\circ} \mathrm{K}$ and of the liquid above $200{ }^{\circ} \mathrm{K}$. Analytical expressions are given for the properties of the crystal and liquid above $200^{\circ} \mathrm{K}$. For the crystal, a modified Einstein function was used to adjust the melting temperature to $414.3^{\circ} \mathrm{K}$. Values between 975 and $1025 \mathrm{cal} / \mathrm{mole}$ for the heat of fusion were found to be the ones most consistent with the data. Comparison of the results with polyethylene data shows reasonable agreement.
\end{abstract}

\section{Introduction}

This paper concerns the empirical determination of accurate values for the thermodynamic properties of ideal $\mathrm{CH}_{2}$-chain crystal ${ }^{1}$ and liquid in the temperature range from 0 to $420{ }^{\circ} \mathrm{K}$ and 200 to $420{ }^{\circ} \mathrm{K}$ respectively, using published data on pure $n$-paraffins. This analysis is intended to circumvent the inherent difficulties involved in measuring polyethylene directly since (so far) even the most carefully crystallized polyethylene samples are not large, well deifined $\mathrm{CH}_{2}$-chain systems, and measurements necessarily reflect the nonnegligible effects of chain folds and "amorphous" inclusions. Wunderlich [1], ${ }^{2}$ realizing this problem, has extrapolated speciiic heats to 100 percent crystallinity to obtain the crystalline $\mathrm{CH}_{2}$ contribution to the specific heat. This method is presently limited in accuracy by a scarcity of data and variations in the chemical structures (e.g., degree of branching and molecular weight) which exist between samples of different crystallinity. Even ideally, if one had sufficient data on several polyethylene samples which differed in percent crystallinity, the extrapolated results might still reflect the presence of chain folded lamellar surfaces, unless the lamellar thicknesses were properly taken into account.

The use of $n$-paraffin data to determine $\mathrm{CH}_{2}$ properties offers the advantages that the $n$-paraffins can be made highly pure and crystallized to a high

1 This means a crystal, large in all dimensions, of very long $\mathrm{CH}_{2}$ chain mole cules, which contains no chain ends or branches and only an equilibrium number of defects.

2 Figures in brackets indicate the literature references at the end of this pa per. degree of perfection. Very carefully measured specific heat data are available for pure $n$-paraffins from $n-\mathrm{C}_{6} \mathrm{H}_{14}$ through $n-\mathrm{C}_{18} \mathrm{H}_{38}$ (see following section). It has been reported that the molar specific heat $\left(C_{p}\right){ }^{3}$ enthalpy $(H)$, entropy $(S)$, and Gibbs free energy $(F)$ of the solid $n$-paraffins appear to be linear with chain length at constant temperature and crystal phase [2-4]. An obvious interpretation of this observation is that each $\mathrm{CH}_{2}$ unit in the chain can be thought of as contributing a certain number of vibrational modes to the crystal without changing the frequency spectrum, and that this contribution is independent of the length of the chain in which the unit is located, so long as the local crystal structure remains unchanged. Accordingly, the properties of a $\mathrm{CH}_{2}$ unit should be the same in a large ideal $-\mathrm{CH}_{2}-$ crystal as in the $n$-paraffins. The major limitation to the $n$-paraffin determination of the crystalline $\mathrm{CH}_{2}$ properties are the deviations from linearity with chain length which become appreciable at temperatures near the $n$-paraffin melting points.

For the liquid phase, there is a slight but real departure from linearity which will necessitate special treatment in the determination of the liquid phase properties.

The approach used below will be: (a) To establish the best values for $C_{p}, H, S$, and $F$ of a $-\mathrm{CH}_{2}-$ unit in both the liquid and solid phases over as wide a range of temperatures as possible, (b) to establish a consistent analytical representation of the above

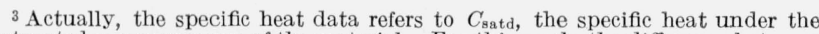
saturated vapor pressure of the material. For this work, the difference between $C_{p}$ and $C_{\text {satd }}$ for the solid and liquid phases of the $n$-paraffins is negligible. 
data from 200 to $420{ }^{\circ} \mathrm{K}$, and (c) to compare the results with actual data on polyethylene and examine the discrepancies between the predicted and observed properties.

\section{Source of Data}

The $n$-paraffin data used in this study were furnished by the United States Bureau of Mines, Bartlesville, Okla., in the form of tables of values for $C_{p}, H-H_{0}, S$, and $F-H_{0}\left(H_{0}\right.$ is the enthalpy at $\left.0{ }^{\circ} \mathrm{K}\right)$. Their work on $n-\mathrm{C}_{6} \mathrm{H}_{14}, \quad n-\mathrm{C}_{7} \mathrm{H}_{16}, \quad$ and $n-\mathrm{C}_{8} \mathrm{H}_{18}$ through $n-\mathrm{C}_{16} \mathrm{H}_{34}$ is presented, together with details of sample purity, measurement techniques, and thermodynamic calculations, in references $[5,6$, and 7] respectively, and their work on $n-\mathrm{C}_{17} \mathrm{H}_{36}$ and $n-\mathrm{C}_{18} \mathrm{H}_{38}$ is as yet unpublished. The data on $n-\mathrm{C}_{7} \mathrm{H}_{16}, n-\mathrm{C}_{17} \mathrm{H}_{36}$ and $n-\mathrm{C}_{18} \mathrm{H}_{38}$ covered the temperature range from 0 to $370^{\circ} \mathrm{K}$, and data for the remaining paraffins extended from 0 to $320^{\circ} \mathrm{K}$.

\section{3. $\mathrm{CH}_{2}$ Structures}

The even $n$-paraffins ${ }^{4}$ from $\mathrm{C}_{6} \mathrm{H}_{14}$ through $\mathrm{C}_{18} \mathrm{H}_{38}$ are triclinic at all temperatures up to the melting point. The odd $n$-paraffins ${ }^{4}$ from $\mathrm{C}_{11} \mathrm{H}_{24}$ through $\mathrm{C}_{17} \mathrm{H}_{36}$ are orthorhombic at all temperatures up to within 15 degrees of their melting points but undergo a solid-solid transition prior to melting. The orthorhombic $\mathrm{CH}_{2}$ structure of the odd paraffins appears to be identical to the $\mathrm{CH}_{2}$ structure of polyethylene, and is assumed to be identical to the structure of the ideal $\mathrm{CH}_{2}$-chain crystal whose properties we are predicting. Although one would not expect the data for the triclinic structure of the even $n$ paraffins to be relevant to this work, it was found that the data obtained from the even $n$-paraffins varied only slightly from that of the odd $n$-paraffins.

In the liquid state one expects and finds no evenodd differences among the paraffins. The absolute entropies of all 13 paraffins examined here, when plotted against chain length, lie on the same, nearly linear curve and the enthalpies and free energies show a similar behavior if one takes into account the differences in zero point enthalpies between the different solid structures. For instance, the enthalpy which had to be added to $F$ and $H$ for the even paraffins in order to have the liquid phase values of $F$ and $H$ for both even and odd paraffins lie on the same nearly linear curve, when plotted versus $n$, was found to be $370 \pm 10 \mathrm{cal} / \mathrm{mole}$ of paraffin molecules. This zero point energy difference is independent of chain length since it results entirely from the differences in packing of the chain end groups, with the triclinic phase allowing the lowest energy packing. ${ }^{5}$

Whereas the solid phase of very linear, high molecular weight polyethylene contains a significant volume of chain folds which cause deviations from the ideal crystalline $\mathrm{CH}_{2}$ specific heats, the liquid state should present no such difficulties. Specific heat measurements should not be able to detect the small per-

1 Even $n$-paraffins and odd $n$-paraffins are terms used here to mean $n$-paraffins containing an even or odd number of carbon atoms in the molecule.

5 See reference [3] for a further discussion of the above points. centage of chain ends and branches present in the liquid. Therefore, the specinic heats and absolute entropies calculated here from the liquid $n$-paraffin data should be close to the actual measured values for polyethylene, and a comparison of predicted and experimental properties of the liquid provides an experimental test of this work. The liquid paraffin data should not, however, be expected to reflect the presence of a glassy state even well below the temperature where the ideal $\mathrm{CH}_{2}$-chain liquid might become a glass.

\section{Analysis of the Paraffin Data}

Table 1 contains a sample of the thermodynamic data as received for the solid and liquid phases at representative temperatures.

For the solid at a given temperature, the differences between the thermodynamic values of consecutive even and consecutive odd compounds was computed and these differences were averaged over the whole range of compounds for which data were available at that temperature. The averages for the even and odd paraffins were found to be very similar, and the combined average for both even and odd compounds was divided by two to obtain the desired thermodynamic value per mole of $\mathrm{CH}_{2}$ units.

At the higher temperatures, where the shorter paraffins are liquid, the accuracy of the computations decreases due to the decreased range of data and the premelting ${ }^{6}$ increase in the specific heat that begins about 50 degrees below the melting point and which can be seen in the data at $200{ }^{\circ} \mathrm{K}$ in table 1 . It is probable that above $200{ }^{\circ} \mathrm{K}$, the values calculated by the above procedure will be somewhat smaller than the correct values.

For the liquid phase data, the range of temperatures amenable to computation was limited at low temperatures by the decrease in the number of liquid samples and at high temperatures $\left(370{ }^{\circ} \mathrm{K}\right)$ by the termination of experimental measurements. The most reliable values are those around $300{ }^{\circ} \mathrm{K}$ where most data exist.

The differences between the thermodynamic values for consecutive even and odd paraffins are not quite as constant for the liquid as for the solid as can be seen in table 1 , and an appropriate extrapolation of these differences to $n=\infty$ was considered to be preferable to using a simple average. When plotted versus $1 / n$, the differences for the liquid were found to be linear within experimental error. For $F, H$, and $S$, the best linear extrapolation to $1 / n=0$ was graphically determined, and the resulting intercept was chosen as the desired thermodynamic value. For $C_{p}$, this $1 / n$ extrapolation gave values which exhibited excessive scatter. It was found that this scatter could be reduced by integrating the $C_{n}$ data, extrapolating the integrated values to $1 / n=0$ and then differentiating the extrapolated integrated values to obtain the desired extrapolated $C_{p}$ values. In practice, this process merely involved

We are not here concerned with the distinction between homophase premelting and impurity induced heterophase premelting. 


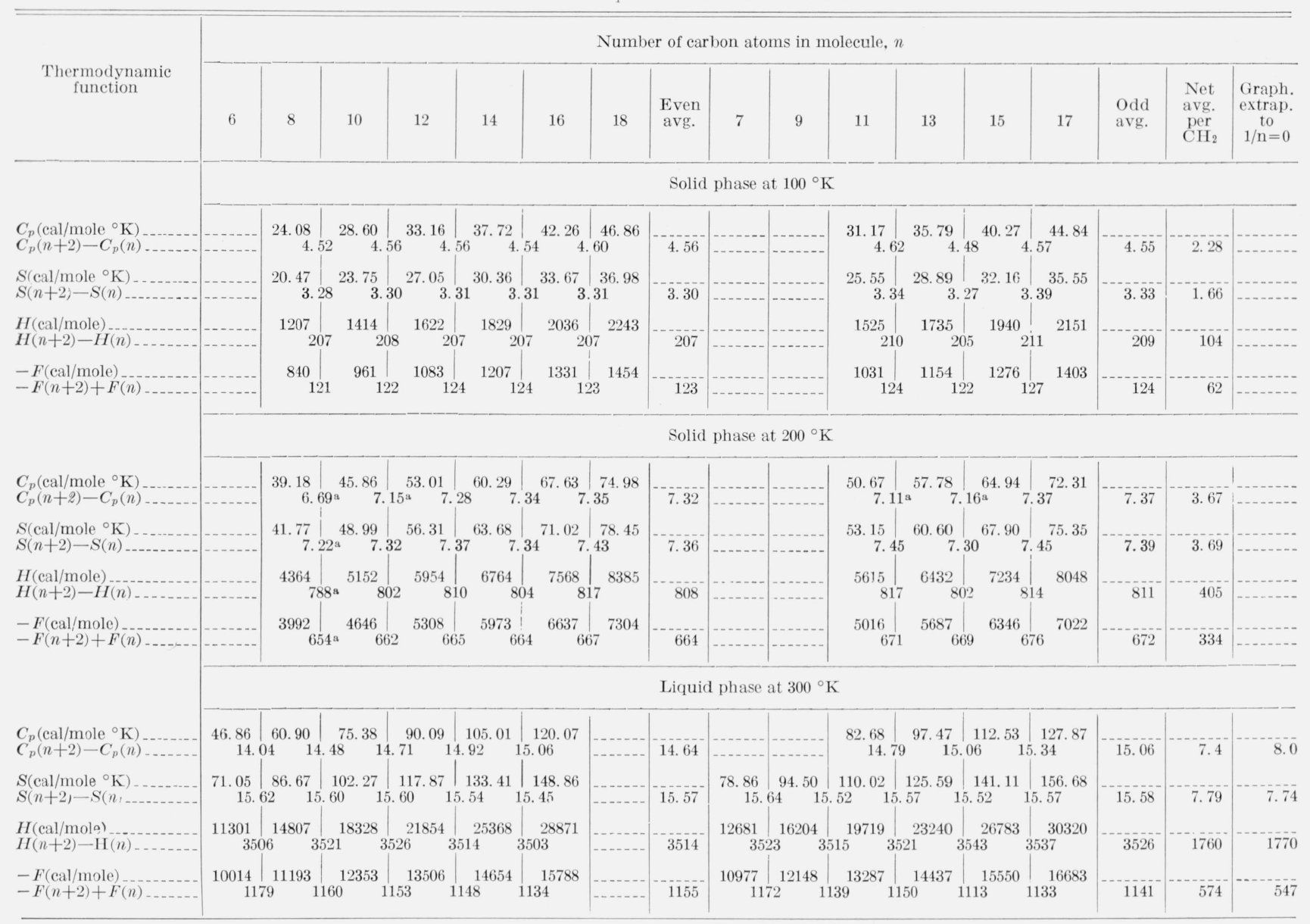

a These values are low because of premelting and were omitted from the calculations.

taking differences between the consecutive experimental $H$ values in table 2 and dividing by $10^{\circ}$. For example, $C_{p}$ (per mole of $\mathrm{CH}_{2}$ units) at $305{ }^{\circ} \mathrm{K}$ was taken to equal $H$ (per mole of $\mathrm{CH}_{2}$ units) at $310^{\circ} \mathrm{K}$ minus $H$ (per mole of $\mathrm{CH}_{2}$ units) at $300{ }^{\circ} \mathrm{K}$ divided by $10^{\circ}$. The same procedure was followed (though mathematically, less precisely) using the TS data, in order to increase the number of available $C_{p}$ values.

The results of the above determinations are listed in table 2 and are represented graphically as closed circles in figures 1 through 4 . The large number of digits given in the calculated value columns in table 2 is not intended to indicate significant figures but is included only for internal consistency.

\section{Determination of Analytical Expressions}

Linear least squares fits of the specific heats for the solid above $150{ }^{\circ} \mathrm{K}$ and specific heats for the liquid above $200{ }^{\circ} \mathrm{K}$ as a function of temperature were carried out. The calculated standard deviations were $0.15 \mathrm{c} \mathrm{l} /$ mole $^{\circ}{ }^{\circ} \mathrm{K}$ for the solid (39 data points) and 0.84 cal mole- ${ }^{\circ} \mathrm{K}$ for the liquid (36 data points). Integrations of $C_{p}$ and $C_{p} / T$ were then carried out and the average values of the constants of integra- tion were determined from the entropy and enthalpy data. The resulting functions fit the $H$ and $S$ data for the solid above $200^{\circ} \mathrm{K}$ with a standard deviation of $2 \mathrm{cal} / \mathrm{mole}$ and $0.01 \mathrm{cal} / \mathrm{mole}^{\circ} \mathrm{K}$, respectively, and for the liquid above $200{ }^{\circ} \mathrm{K}$ with a standard deviation of $6 \mathrm{cal} / \mathrm{mole}$ and $0.02 \mathrm{cal} / \mathrm{mole}-{ }^{\circ} \mathrm{K}$, respectively. The Gibbs free energy was computed directly from $H$ and $S$ and was found to fit the free energy data above $200{ }^{\circ} \mathrm{K}$ with a standard deviation of $4 \mathrm{cal} / \mathrm{mole}$ for the solid and $9 \mathrm{cal} / \mathrm{mole}$ for the liquid.

By using the calculated analytical expressions to extrapolate up to the temperature where the free energies for the solid and liquid become equal, it was found that the predicted melting point was 397.4 ${ }^{\circ} \mathrm{K}$ and the predicted heat of fusion was $1132 \mathrm{cal} /$ mole. Since the predicted melting point is 4 percent below its most probable value of $414.3^{\circ} \mathrm{K}$ [4] and since the predicted heat of fusion seems unreasonably high, the assumption of a linear specific heat for the solid above $200^{\circ} \mathrm{K}$ was concluded to be inadequate for the representation of the known data. Hence, a correction to the specific heat for the solid was sought that would decrease the free energy of the solid by a sufficient amount to increase the melting point to its previously determined most probable 
TABLE 2. Values of the molar specific heats $\left(\mathrm{C}_{\mathrm{p}}\right)$ enthalpies $\left(\mathrm{H}-\mathrm{H}_{0}\right)$, entropies (S) and Gibbs free energies $\left(\mathrm{F}-\mathrm{H}_{0}\right)$ of ideal $\mathrm{CH}_{2}$ chain crystal and liquid as derived from n-paraffin data (experimental values) and as calculated using the equations in table 3

\begin{tabular}{|c|c|c|c|c|c|c|c|c|}
\hline \multirow{2}{*}{$\begin{array}{l}\text { Tem- } \\
\text { pera- } \\
\text { ture }\end{array}$} & \multicolumn{2}{|c|}{$\begin{array}{c}C_{p}(\mathrm{cal} / \mathrm{mole} \\
\stackrel{\circ}{\mathrm{K}})\end{array}$} & \multicolumn{2}{|c|}{$H-H_{0}(\mathrm{cal} / \mathrm{mole})$} & \multicolumn{2}{|c|}{$\begin{array}{c}S(\mathrm{cal} / \text { mole } \\
\left.{ }^{\circ} \mathrm{K}\right)\end{array}$} & \multicolumn{2}{|c|}{$\begin{array}{l}-\left(F-H_{0}\right) \\
(\mathrm{cal} / \mathrm{mole})\end{array}$} \\
\hline & exp. & calc. & exp. & ealc. & exp. & calc. & exp. & calc. \\
\hline & \multicolumn{8}{|c|}{ Solid phase } \\
\hline $\begin{array}{l}{ }^{\circ} \mathrm{K} \\
10\end{array}$ & 0.025 & & 0.06 & & & & & \\
\hline 20 & $\begin{array}{l}.020 \\
.15\end{array}$ & . & $\begin{array}{l}0.00 \\
.85\end{array}$ & & $\begin{array}{r}0.01 \\
.05\end{array}$ & & $\begin{array}{r}0.02 \\
.30\end{array}$ & \\
\hline 30 & .39 & --..-- & $\begin{array}{l}3.50 \\
0.00\end{array}$ & & .16 & & 1. 34 & \\
\hline $\begin{array}{l}40 \\
50\end{array}$ & & & $\begin{array}{r}9.00 \\
17.8\end{array}$ & & .32 & & 3.7 & \\
\hline $\begin{array}{l}50 \\
60\end{array}$ & $\begin{array}{l}1.03 \\
1.34\end{array}$ & -... & $\begin{array}{l}17.8 \\
29.5\end{array}$ & & .51 & & 7.8 & \\
\hline $\begin{array}{l}60 \\
70\end{array}$ & $\begin{array}{l}1.34 \\
1.63\end{array}$ & ........ & $\begin{array}{l}29.5 \\
44.6\end{array}$ & & .73 & & 14. 0 & \\
\hline 80 & $\begin{array}{l}1.00 \\
1.88\end{array}$ & & & 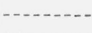 & .95 & $\cdots$ & 22.4 & \\
\hline 90 & $\begin{array}{l}1.88 \\
2.10\end{array}$ & ....... & $\begin{array}{l}62.0 \\
82.0\end{array}$ & & $\begin{array}{l}1.19 \\
1.43\end{array}$ & -...-. & 33. 2 & \\
\hline 100 & 2.28 & ......... & 104 & & $\begin{array}{l}\text { 1. } 43 \\
\text { 1. } 66\end{array}$ & & $\begin{array}{l}46.2 \\
61.7\end{array}$ & \\
\hline 110 & 2.45 & - & 128 & & 1. 88 & & 79 & \\
\hline 120 & 2.60 & ..... & 153 & & $\begin{array}{l}1.00 \\
2.10\end{array}$ & & 99 & \\
\hline 130 & 2.75 & & 180 & & $\begin{array}{l}\text { 2. } 30 \\
\text { 2. }\end{array}$ & & 121 & \\
\hline 140 & 2.89 & & 208 & & $\begin{array}{l}2.02 \\
2.52\end{array}$ & & $\begin{array}{l}121 \\
146\end{array}$ & \\
\hline 150 & 3. 05 & 3.02 & 237 & & 2.73 & & 171 & \\
\hline 160 & 3. 16 & 3.17 & 268 & & 2. 92 & & $\begin{array}{l}171 \\
200\end{array}$ & \\
\hline 170 & 3. 28 & 3. 32 & 300 & & 3.12 & & 230 & \\
\hline 180 & 3. 40 & $\begin{array}{l}\text { 3. } 48 \\
\text { 3. }\end{array}$ & 334 & & $\begin{array}{l}\text { 3. } 32 \\
\text { 3. } 31\end{array}$ & 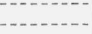 & 263 & \\
\hline 190 & 3. 52 & $\begin{array}{l}0.65 \\
3.65\end{array}$ & $\begin{array}{l}364 \\
369\end{array}$ & & 3.51 & & 297 & \\
\hline 200 & 3. 67 & 3. 8572 & 405 & 405.88 & 3.69 & 3. 7201 & 334 & 338.14 \\
\hline 210 & 3. 81 & 4. 0378 & 441 & 445.35 & 3.87 & 3. 9127 & 371 & 376.30 \\
\hline 220 & $\begin{array}{l}\text { O. } 3.91 \\
3.95\end{array}$ & 4. 2224 & 479 & 486.64 & 4.05 & 4. 1046 & 410 & 416.39 \\
\hline 230 & $\begin{array}{l}0.90 \\
4.05\end{array}$ & 4. 4107 & 519 & 529.78 & 4. 23 & 4. 2963 & 453 & 458.39 \\
\hline 240 & $\begin{array}{l}4.16 \\
4.16\end{array}$ & 4. 6028 & 562 & 574.85 & 4. 41 & 4. 4881 & 496 & 502.31 \\
\hline 250 & 4. 32 & 4. 7975 & 603 & 621.84 & 4. 58 & 4. 6799 & 541 & 548.15 \\
\hline 260 & & 4. 9936 & 647 & 670.76 & 4.77 & 4. 8717 & 590 & 595. 90 \\
\hline 270 & & 5. 1924 & 691 & 721.70 & 4. 94 & 5. 0640 & 643 & 645.59 \\
\hline 280 & $\ldots$ & 5. 3909 & 742 & 774.57 & 5. 13 & 5. 2562 & 695 & 697.18 \\
\hline 290 & & 5. 5838 & 790 & 829.37 & 5. 30 & 5. 4484 & 748 & 750.67 \\
\hline 300 & - & 5. 7898 & & 886.34 & 0.50 & $\begin{array}{l}\text { 0. } \\
5.6416\end{array}$ & 148 & $\begin{array}{l}700.15 \\
806.15\end{array}$ \\
\hline 310 & & 5. 9909 & & $\begin{array}{l}800.04 \\
945.19\end{array}$ & & $\begin{array}{l}.0 .0110 \\
5.8345\end{array}$ & & $\begin{array}{l}800.15 \\
863.15\end{array}$ \\
\hline 320 & & 6.1851 & & $\begin{array}{l}9+0.19 \\
1005.91\end{array}$ & & $\begin{array}{l}5.80340 \\
6.0272\end{array}$ & & $\begin{array}{l}803.15 \\
922.79\end{array}$ \\
\hline 330 & & 6.3836 & & $\begin{array}{l}1068.81 \\
1068.84\end{array}$ & & $\begin{array}{l}\text { 0. } \\
\text { 6. } 2208\end{array}$ & & 983.51 \\
\hline 340 & $\ldots$ & 6.5795 & & $\begin{array}{l}1133.64 \\
\end{array}$ & & $\begin{array}{l}0.4142 \\
6.42\end{array}$ & & 1047.20 \\
\hline 350 & -- & 6. 7734 & & 1200.32 & & 6. 6075 & & 1112.31 \\
\hline 360 & $\ldots$ & 6. 6629 & & 1268.71 & $\cdots$ & 6.7999 & & $\begin{array}{l}1179.27 \\
1179.27\end{array}$ \\
\hline 370 & 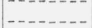 & 7. 1553 & & 1339.47 & $\ldots$ & 6. 9939 & & 1248.29 \\
\hline 380 & 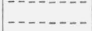 & 7. 3421 & & 1411. 78 & $\ldots$ & 7.1865 & & 1319.13 \\
\hline 390 & -1 & 7. 5293 & & 1486.17 & & 7. 3798 & & 1390.97 \\
\hline 400 & $\ldots$ & 7.7141 & & 1562.37 & & 7. 5727 & & 1466.73 \\
\hline 410 & & 7. 8966 & & 1640.42 & & 7. 7654 & & 1543.41 \\
\hline \multirow{3}{*}{$\begin{array}{l}414.3 \\
420\end{array}$} & & 7. 9748 & & 1674.52 & & 7. 8482 & & 1576.98 \\
\hline & $\ldots$ & 8.0761 & & 1720.26 & & 7. 9578 & & 1622.03 \\
\hline & \multicolumn{8}{|c|}{ Liquid phase } \\
\hline 200 & a 6.8 & 6. 6360 & 1076 & 1064.60 & 4.83 & 4. 8676 & -110 & -91.08 \\
\hline 210 & & 6. 6178 & 1144 & $\begin{array}{l}1131.30 \\
1131.3\end{array}$ & $\begin{array}{l}\text { 4.83 } \\
5.16\end{array}$ & $\begin{array}{l}4.8060 \\
5.1934\end{array}$ & $\begin{array}{l}-110 \\
-58\end{array}$ & $\begin{array}{l}-91.08 \\
-40.77\end{array}$ \\
\hline 220 & 6.95 & 6. 7996 & 1203 & 1198. 96 & 5.5 & 5. 5078 & 4 & 12.75 \\
\hline 230 & 7.0 & 6. 8814 & 1274 & $\begin{array}{l}1267.36 \\
170\end{array}$ & 5.8 & 5.8118 & 62 & 69.35 \\
\hline 240 & 6.4 & 6. 9632 & 1343 & 1336.58 & 6.10 & 6.1064 & 124 & $\begin{array}{l}128.95 \\
\end{array}$ \\
\hline 250 & 7.05 & 7. 0450 & 1405 & 1406. 62 & 6. 6.37 & 6. 3923 & 187 & 191. 44 \\
\hline 260 & 7.0 & 7. 1268 & 1475 & 1477.48 & 6.65 & 6702 & 253 & 256.76 \\
\hline 270 & 7. 25 & 7. 2086 & 1544 & & 6.9 & 6.9407 & 324 & 324.83 \\
\hline 280 & 7.35 & 7. 2904 & 1615 & 1621. 66 & 7. 1 & 7. 2044 & 398 & 395.57 \\
\hline 290 & 8.4 & 7. 3722 & 1688 & 1694.97 & 7.4 & 7. 4616 & 470 & 468. 90 \\
\hline 300 & $\begin{array}{l}7.4 \\
7.7\end{array}$ & 7.4540 & 1770 & 1769. 10 & 7.7 & 7. 7129 & 547 & 544. 77 \\
\hline 310 & 6.75 & 7.5358 & 1845 & 1844.05 & 8.1 & 7. 9586 & 628 & 623.13 \\
\hline 320 & 7.7 & 7. 6176 & 1911 & 1919.82 & 8.2 & 8.1992 & 719 & 703.93 \\
\hline 330 & 7.6 & 7.6984 & 2000 & 1996. 40 & 8.4 & 8. 4348 & 794 & 787.10 \\
\hline 340 & 7.6 & 7. 7812 & 2072 & 2073. 80 & 8.6 & 8. 6660 & 883 & 872.62 \\
\hline 350 & 7. 55 & 7.8630 & 2152 & 2152. 02 & 8.9 & 8. 8926 & 968 & 960.40 \\
\hline 360 & 7. 95 & 7.9448 & 2225 & 2231.06 & 9.1 & 9.1153 & 1062 & 1050.44 \\
\hline 370 & 8.5 & 8. 0266 & 2304 & 2310.92 & 9.34 & 9.3341 & 1154 & 1142,70 \\
\hline 380 & & 8.1084 & 2392 & 2391.60 & 9.56 & $\begin{array}{l}\text { 3. } \\
\text { 9. } 54971\end{array}$ & 1241 & 1237.12 \\
\hline 390 & & $\begin{array}{l}0.104 \\
8.1902\end{array}$ & & 2473.09 & & $\begin{array}{l}\text { 9. } 04912 \\
\text { 9. }\end{array}$ & 1241 & 1333.68 \\
\hline 400 & & 8.2720 & $\ldots$ & 2555.40 & 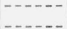 & 9.6693 & & $\begin{array}{l}1030.08 \\
1432.32\end{array}$ \\
\hline 410 & & 8.3538 & & 2638.53 & & 10. 1746 & & 1533.06 \\
\hline 414. 3 & & 8.3890 & & $\begin{array}{l}2608.50 \\
2674\end{array}$ & & $\begin{array}{l}\text { 10. } 10 \\
\text { 10. } 2619\end{array}$ & & $\begin{array}{l}133.076 .9 \\
1576.9\end{array}$ \\
\hline 420 & & 8. 4356 & & 2722.48 & & 10. 3768 & & 1635.80 \\
\hline
\end{tabular}

a This column refers to temperatures $5^{\circ}$ higher than indicated; e.g., 6.8 is the $C_{p}$ value at $205^{\circ} \mathrm{K}$.

value, and at the same time the correction was desired to have as little effect as possible on the linear thermodynamic functions for the solid below $300{ }^{\circ} \mathrm{K}$ where a good fit of the data was already obtained.

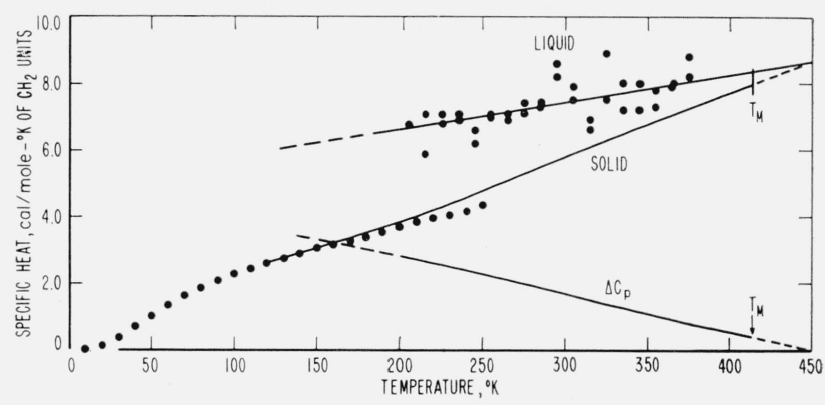

Figure 1. Predicted specific heats, $\mathrm{C}_{\mathrm{p}}$, of an ideal $\mathrm{CH}_{2-}$ chain crystal and liquid as a function of temperature.

The closed circles represent values calculated from $n$-paraffin data, samples of which are listed in table 1, and the solid curves were calculated from the equations in table 3.

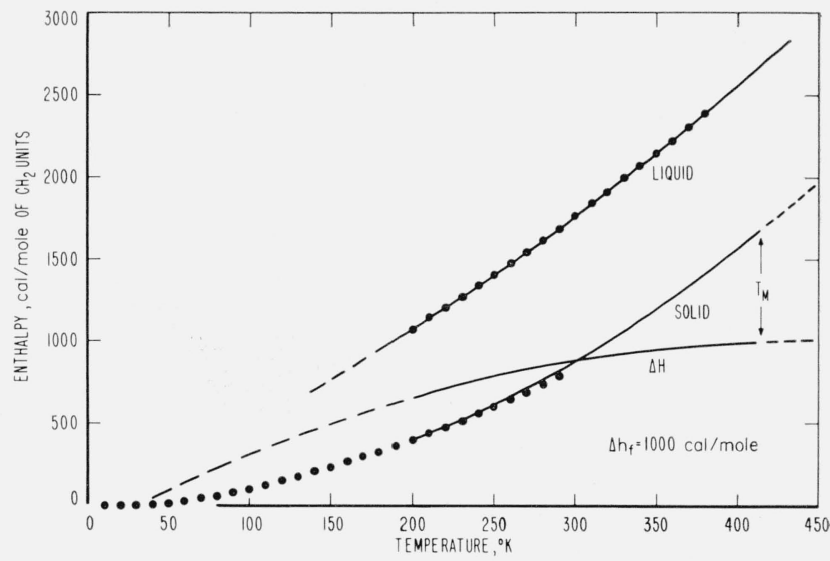

Figure 2. Predicted enthalpies $\left(\mathrm{H}-\mathrm{H}_{0}\right)$, of an ideal $\mathrm{CH}_{2-}$ chain crystal and liquid as a function of temperature.

The closed circles represent values calculated from $n$-paraffin data, samples of which are listed in table 1 , and the solid curves were calculated from the equations in table 3.

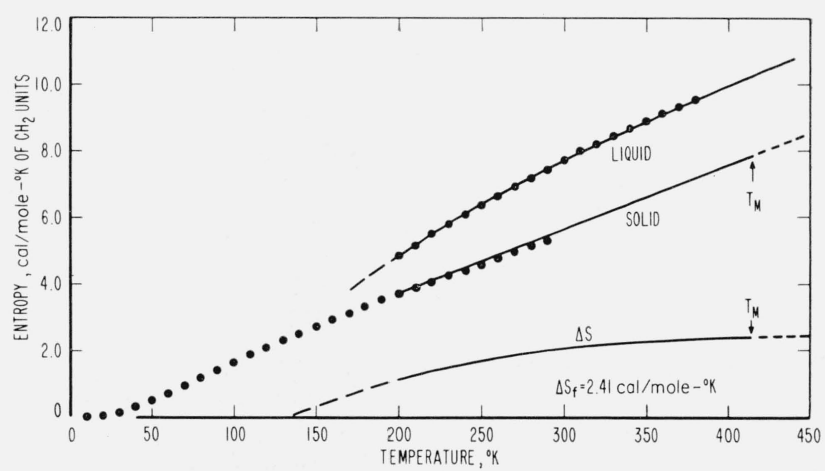

Figure 3. Predicted entropies, $\mathrm{S}$, of an ideal $\mathrm{CH}_{2}$-chain crystal and liquid as a function of temperature

The closed circles represent values calculated from $n$-paraffin data, samples of which are listed in table 1 , and the solid curves were calculated from the equations in table 3. 


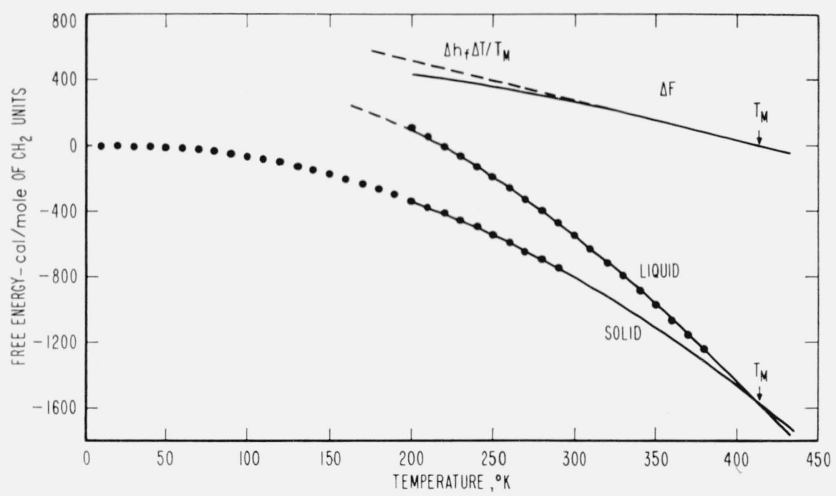

Figure 4. Predicted Gibbs free energies $\left(\mathrm{F}-\mathrm{H}_{0}\right)$ of an ideal $\mathrm{CH}_{2}$-chain crystal and liquid as a function of temperature.

The closed circles represent values calculated from $n$-paraffin data, samples of which are listed in table 1 , and the solid curves were calculated from the equations in table 3 .

Fortunately, a correction of the type implied here by the $n$-paraffin data has the same form as the specific heat contributions due to several independent $\mathrm{CH}_{2}$ vibrations which become important above $250^{\circ} \mathrm{K}[8,9]$. These vibrations are well represented by a summation of Einstein functions of the form $C_{v}=\sum_{i}\left(R \theta_{i}^{2} / T^{2}\right)\left[e^{\theta_{i} / T} /\left(e^{\theta_{i} / T}-1\right)^{2}\right]$. For our use, we have preserved the form of this function but have applied it to $C_{p}$ rather than $C_{v}$ and have made the further approximations that we can use a single term to replace the summation of several terms, and that $\theta>>T$ in the range of interest. That is, we shall assume a correction to $C_{p}$ of the form,

$$
\bar{C}_{p}=\left(\bar{n} R \overline{\theta^{2}} / T^{2}\right) \exp (-\bar{\theta} / T)
$$

where the bar indicates an "effective" quantity which is expected to lie somewhere between the maximum and minimum quantities in the above expression for $C_{v}$. The effective number of independent $\mathrm{CH}_{2}$ modes is represented by $\bar{n}, R$ is the molar gas constant, $\bar{\theta}=h \bar{\nu} / k$ is the characteristic temperature, $h$ is Planck's constant, $\bar{\nu}$ is the effective frequency of vibration, $k$ is Boltzmann's constant, and $T$ is the absolute temperature.

It is convenient to replace the two parameters $\bar{n}$ and $\bar{\theta}$ in eq (1) by two different parameters, $F_{s}$ and $H_{s}$, the corrections to the free energy and enthalpy at $T_{M}$ needed to give the proper melting point and heat of fusion. This replacement is accomplished by integrating eq (1) to find the corresponding $\bar{H}$ and $\bar{F}$ and then solving the equations $H_{s}=\bar{H}$ at $T=T_{M}$ and $F_{s}=\bar{F}$ at $T=T_{M}$ for $\bar{\theta}$ and $\bar{n}$. The result is $\bar{n}=\left(F_{s} / R T_{M}\right) \exp \left(H_{s} / F_{s}\right)$ and $\bar{\theta}=T_{M} H_{s} l$ $F_{s}$. If we assume $T_{M}=414.3{ }^{\circ} \mathrm{K}[4]$ then one finds that $F_{s}$ must equal $-48.80 \mathrm{cal} / \mathrm{mole}$ (calculated from the uncorrected $\Delta F$ at $414.3^{\circ} \mathrm{K}$ ) and $H_{s}$ must equal $\left(1162.10-\Delta h_{f}\right) \mathrm{cal} / \mathrm{mole}$ where $\Delta h_{f}$ is the heat of fusion at $T_{M}=414.3^{\circ} \mathrm{K}$. We have here chosen a value of $\Delta h_{f}=1000 \mathrm{cal} / \mathrm{mole}$ as reasonable, which choice gives $\bar{\theta}=1376$ and $\bar{n}=1.64$.

The resulting analytical expressions for the thermodynamic funtions of the $\mathrm{CH}_{2}$-chain crystal and liquid above $200{ }^{\circ} \mathrm{K}$ are shown in table 3, and the calculated values are compared to the experimental values in table 2 .

TABLE 3. Analytical expressions for the thermodynamic functions of the ideal $\mathrm{CH}_{2}$-chain crystal and liquid above $200{ }^{\circ} \mathrm{K}$, derived from $\mathrm{n}$-paraffin data

\begin{tabular}{|c|c|c|}
\hline Funetion & Solid phase $\left(T \geq 200^{\circ} \mathrm{K}\right)$ & Liquid phase $\left(T \geq 200^{\circ} \mathrm{K}\right.$. $)$ \\
\hline $\begin{array}{l}C_{p} \\
\left(\mathrm{cal} / \mathrm{mole}{ }^{\circ} \mathrm{K}\right)\end{array}$ & $0.0139 T+0.916+22.308 \times 10^{4} u / T^{2}$ & $0.00818 T+5.00$ \\
\hline $\begin{array}{l}H-H_{0} \\
\text { cal } / \text { mole) }\end{array}$ & $0.00695 T^{2}+0.916 T-60+162.10 u$ & $0.00409 T^{2}+5.00 T-99$ \\
\hline$\underset{\left(\mathrm{cal} / \mathrm{mole}^{\circ} \mathrm{K}\right)}{S}$ & $0.0139 T+0.916 \ln T-3.94+(0.117789+162.10 / T) u$ & $0.00818 T+5.00 \ln T-23.26$ \\
\hline \multirow[t]{2}{*}{$\begin{array}{l}F-H_{0} \\
(\mathrm{cal} / \mathrm{mole})\end{array}$} & $-0.00695 T^{2}-0.916 T \ln T+4.856 T-60-0.117789 T u$ & $-0.00409 T^{2}-5.00 T \ln T+28.26 T-99$ \\
\hline & \multicolumn{2}{|c|}{ Liquid-solid difference $\left(T \geq 200^{\circ} \mathrm{K}\right)$} \\
\hline $\begin{array}{l}\Delta C_{p} \\
\left(\mathrm{cal} / \mathrm{mole}^{\circ} \mathrm{K}\right)\end{array}$ & \multicolumn{2}{|l|}{$-0.00572 T+4.84-22.308 \times 10^{4} u / T^{2}$} \\
\hline $\begin{array}{l}\Delta H \\
(\mathrm{cal} / \mathrm{mole})\end{array}$ & \multicolumn{2}{|l|}{$-0.00186 T^{2}+4.84 T-39-162.10 u$} \\
\hline $\begin{array}{l}\Delta S \\
\left(\mathrm{cal} / \mathrm{mole}{ }^{\circ} \mathrm{K}\right)\end{array}$ & \multicolumn{2}{|l|}{$-0.00572 T+4.84 \ln T+19.32-(0.117789+162.10 / T) u$} \\
\hline $\begin{array}{l}\Delta F \\
(\mathrm{cal} / \mathrm{mole})\end{array}$ & \multicolumn{2}{|l|}{$0.00186 T^{2}-4.84 T \ln T+23.404 T-39+0.117789 T u$} \\
\hline
\end{tabular}

$u=\exp [-3.32172(414.3-T) / T]$ 


\section{Discussion}

\subsection{Reliability of the Results}

It is important to have some idea of how accurately the results listed in table 2 represent the properties of an ideal $\mathrm{CH}_{2}$-chain compound. The specific heats below $150{ }^{\circ} \mathrm{K}$ and $H, S$, and $F$ below $200{ }^{\circ} \mathrm{K}$ are probably accurate to \pm 1 percent judging from the consistency of the averaged values (examples in table 1) and the estimate of better than 1 percent accuracy for the original data. At $200^{\circ} \mathrm{K}$ the effects of premelting can be seen in table 1 as a reduction in the first two specific heat differences and the first $H, S$, and $F$ differences. One is increasingly uncertain above $200{ }^{\circ} \mathrm{K}$ about the correctness of the averaged data values, and thus the calculated values are to be preferred at the higher temperatures. All reasonable attempts to alter the results by starting with different initial linear and quadratic specific heat functions did not change the predicted melting point by more than 2 degrees or the predicted heat of fusion by more than $5 \mathrm{cal} / \mathrm{mole}$. Nor did different assumed forms of the correction term make a significant difference in the predicted thermodynamic functions. The results were found to be quite insensitive to artifacts in the data or initial assumptions. This insensitivity, while giving one confidence in the preducted values, greatly reduces the importance which one can attribute to the values of $\bar{\theta}$ and $\bar{n}$ in eq (1).

The most uncertain and sensitive parameter in the calculations is the heat of fusion, $\Delta h_{f}$. The best current experimental estimate of $\Delta h_{f}$ for polyethylene by the diluent method is $970 \mathrm{cal} / \mathrm{mole}$ [10]. A reasonable calculation shows that for the ideal $\mathrm{CH}_{2}$-chain crystal, $\Delta h_{f}$ can be expected to be higher than for $100 \mathrm{~A}$ thick lamellar polyethylene by 2 to 3 percent. From our work, $\Delta h_{f}=975.9$ appears to be a minimum value since any lower value results in the solid specific heat exceeding the liquid specific heat below the melting point. As $\Delta h_{f}$ is increased above its minimum value, the deviation between the calculated and experimental values in the 200 to $290{ }^{\circ} \mathrm{K}$ range increases, and the values of $\bar{\theta}$ and $\bar{n}$ in eq (1) decrease from $1580^{\circ} \mathrm{K}$ and 2.70 for $\Delta h_{f}=976$ to $1376{ }^{\circ} \mathrm{K}$ and 1.64 for $\Delta h_{f}=1000 \mathrm{cal} / \mathrm{mole}$ and $1164{ }^{\circ} \mathrm{K}$ and 0.98 for $\Delta h_{f}=1025$. If $\Delta h_{f}$ is as large as $1025 \mathrm{cal} / \mathrm{mole}$, both the deviation from the experimental data and the values of $\bar{\theta}$ and $\bar{n}$ seem unreasonable. Thus it appears likely that the correct value of $\Delta h_{f}$ lies within \pm 2.5 percent of the $1000 \mathrm{cal} / \mathrm{mole}$ assumed in this analysis.

The \pm 2.5 percent error in $\Delta h_{f}$ causes an uncertainty in $H$ and $S$ for the solid which decreases rapidly with temperature from about 1 percent at $400^{\circ} \mathrm{K}$ to a negligible error at $300^{\circ} \mathrm{K}$. 'The effect of the uncertainty in $\Delta h_{f}$ on the specific heat is illustrated in figure 5 .

For the liquid phase, the standard deviations of the data from the calculated curve have been given in the previous section and amount to roughly 10 percent for $C_{p}, 2$ percent for $F$, and 0.3 percent for

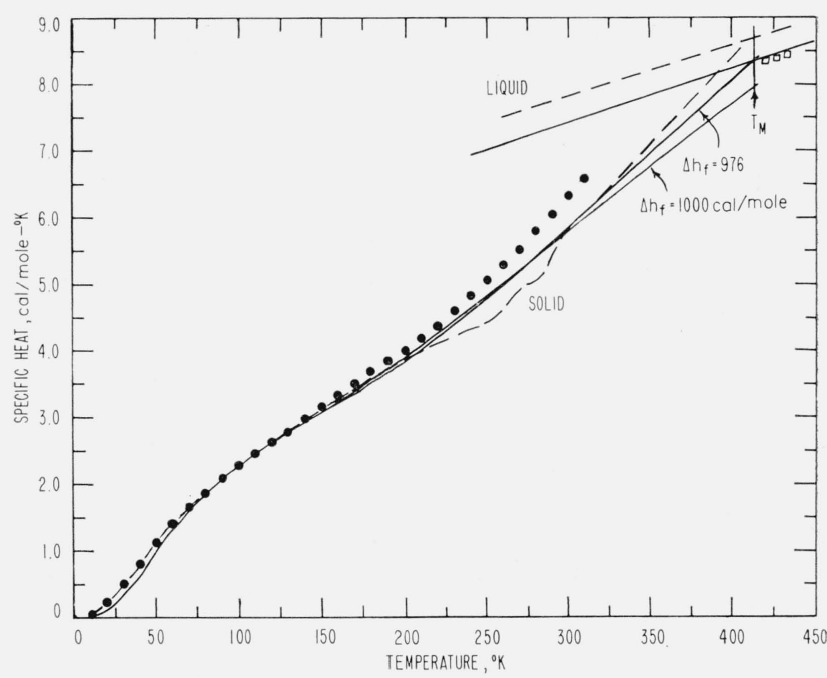

Figure 5. The predicted specific heats, $\mathrm{C}_{\mathrm{p}}$, of an ideal $\mathrm{CH}_{2-}$ chain crystal and liquid (solid curves) for two assumed heats of fusion, compared to the extrapolated values given by Wunderlich for completely crystalline polyethylene (dashed curve) and the polyethylene data of Dainton, Evans, Hoare, and Melia (closed circles) and Passaglia and Kevorkian (open squares).

$H$ and $S$. Hence, it seems reasonable to expect the calculated $H$ and $S$ values to be accurate to within \pm 2 percent. A comparison with polyethylene liquid data in the next section supports an estimate of \pm 2 percent reliability for the liquid $C_{p}$ values as well as the $H$ and $S$ values.

\subsection{Comparison With Experiment}

Figure 5 shows a comparison of the ideal specific heat predicted here from $n$-paraffin data with that predicted by Wunderlich [1] from polyethylene data and with actual experimental values for crystalline Marlex 50 as reported recently by Passaglia and Kevorkian [9] and Dainton, Evans, Hoare, and Melia [11]. The speciiic heat values predicted here are appreciably lower than the polyethylene values up to $80^{\circ} \mathrm{K}$, slightly larger from 80 to $140^{\circ} \mathrm{K}$ (this range varies somewhat with different data) and again smaller at higher temperatures. The smoothness (smaller variations in the slope) of the experimental $C_{p}$ curve relative to the predicted curve below room temperature indicates that the ideal vibrational frequency distribution is broadened and the characteristic temperature is lowered in actual specimens of polyethylene - a result attributable to imperfections. Similar behavior was noted during this study in $C_{p}$ data for a sample of $n-\mathrm{C}_{32} \mathrm{H}_{66}$ and a less pure sample of $n-\mathrm{C}_{33} \mathrm{H}_{68}$. Whereas the $\mathrm{C}_{33}$ specific heats were nearly linear with temperature from 90 to $180{ }^{\circ} \mathrm{K}$, the $\mathrm{C}_{32}$ specific heats were markedly sigmoidal in the same temperature range with values below those of $\mathrm{C}_{33}$ at high and low temperatures and above those of $\mathrm{C}_{33}$ at temperatures between 100 and $150^{\circ} \mathrm{K}$. Liquid polyethylene specific heat data [9], shown as squares in figure 
5 , agree to within 1 percent with the predicted liquid $C_{p}$ curve. The enthalpies of the liquid reported by Passaglia and Kevorkian are smaller than predicted by less than 2 percent and the entropies of the liquid are larger than predicted by less than 2 percent. These agreements are considered satisfactory.

Wunderlich's predicted $H$ and $S$ values for the solid at $300{ }^{\circ} \mathrm{K}$ agree to within 2 percent with those predicted from the $n$-paraffins. The predicted specific heats differ somewhat as shown by the dashed curve in figure 5. Dainton, Evans, Hoare, and Melia [11] used an extrapolation technique to obtain a value for the ideal entropy of polyethylene at $25{ }^{\circ} \mathrm{C}$ of 5.5 $\mathrm{cal} / \mathrm{mole}^{\circ} \mathrm{K}$ in favorable agreement with $5.6 \mathrm{cal} /$ mole ${ }^{\circ} \mathrm{K}$ predicted here.

One important result of this work concerns the thermodynamic crvstallinity scale [i.e., the calculation of the crystalline fraction of a sample from the equation $\chi=[\mathrm{H}$ (liquid) $-\mathrm{H}$ (sample) $] /[\mathrm{H}$ liquid) $-\mathrm{H}$ (crystal)]. The values of $\mathrm{H}$ (liquid) $-\mathrm{H}$ (crystal) calculated in this study are significantly larger than those given by Wunderlich [1], but both the crystalline and liquid enthalpies are smaller, probably because of a zero point enthalpy difference. Such a zero point enthalpy difference is expected if one assumes that the polyethylene extrapolation pertains to an ideally perfect chain folded lamellar crystal rather than the ideally perfect, large nonfolded crystal associated with the paraffin extrapolation. Whereas both types of perfect crystals would have the same zero point entropy (equal to zero by the third law), the zero point enthalpies would be different. It is interesting to note that the Marlex 50 sample measured by Passaglia and Kevorkian [9] has a volume crystallinity of 80.0 percent and an enthalpy crystallinity of 93.8 percent as determined from the values of Wunderlich and Dole [12], and using enthalpy values from this work, 97 percent or 93.5 percent, depending upon whether one uses the solid at $0^{\circ} \mathrm{K}$ or the liquid above $T_{M}$ as the reference state. The zero point enthalpy correction which had to be added for the latter calculation was 40 cal $/$ mole of folds. The fact that thermodynamic crystallinities are generally higher than volume crystallinities is consistent with the assumption that much of the imperfection in highly crystalline polyethylene samples is unoccupied volume (such as might be expected to exist between lamellar fold surfaces.) Volume measurements would be sensitive to these defects whereas enthalpy measurements would not.

\subsection{Observations and Suggestions}

The thermodynamic properties represented in figures 1-4 exhibit several unusual features that result from the high specific heat of the solid at high temperatures (nearly equal to that of the liquid at the melting temperature). The difference $(\Delta H)$ between the enthalpies of the solid and liquid is quite constant in the melting region and the tendency of $\Delta H$ to become negative at low temperatures is not pronounced. Even though $\Delta S$ appears to tend toward zero between 100 and $150{ }^{\circ} \mathrm{K}$, the necessity for polyethylene to form a glass to maintain a positive $\Delta \dot{H}$ and $\Delta S$ is not as obvious as in most substances. It seems likely that the discontinuity in the $\Delta H$ versus temperature curve at the glass transition would be so small that it would be difficult to detect. In accord with the above, $\Delta F$ is well approximated by $\Delta h_{f} \Delta T / T_{M}$ over an unusually large range of temperatures. This simple linear approximation to $\Delta f$ is in error by only 1.5 percent for $\Delta T=50$ degrees and by less than 5 percent for $\Delta T=100$ degrees. One would expect $\Delta f$ to be much less linear than this for most substances [12]. From the above observations, it is not surprising that there is very little indication of a glass transition in the thermodynamic data for linear polyethylene.

There is no indication in the data derived from the liquid paraffins above $200^{\circ} \mathrm{K}$ of the existence of the glassy state in polyethylene, and yet the glass is generally considered to be the stable amorphous state in polyethylene below about $237^{\circ} \mathrm{K}$ [1]. One may conclude that the glass transition temperature is chain length dependent and that the glass becomes stable with respect to the supercooled liquid above $200^{\circ}$ only for chain lengths greater than some minimum value. The only way one could use the $n$-paraffins for predicting the properties of the polyethylene glassy state would be to have data on the glassy state of the $n$-paraffins.

As shown in table 1, the incremental increase per $\mathrm{CH}_{2}$ in the $n$-paraffin thermodynamic properties is not as constant in the liquid state as in the solid. This result seems consistent with the following argument. In the solid, even for chains with less than $10 \mathrm{CH}_{2}$ units, the intermolecular forces are strong enough compared to the intramolecular forces to isolate the motions of a central $\mathrm{CH}_{2}$ unit from those of the chain ends. In the liquid the intermolecular forces are weaker and less regular so that the $\mathrm{CH}_{2}$ behavior is sensitive to chain end effects. The nonlinearity of the incremental increase per $\mathrm{CH}_{2}$ in the liquid thermodynamic properties with reciprocal chain length possibly indicates the presence of "entire chain" vibrational modes in the liquid even for very long chain lengths. ${ }^{7}$

The departure of the predicted specific heat from that measured for polyethylene in the 10 to 80 ${ }^{\circ} \mathrm{K}$ temperature range should be investigated further. Since all polyethylenes so far measured seem to show the same higher than predicted specific heats in this range, the anomaly would seem to be associated with some nonideal feature which all samples have in common-e.g., chain folded surfaces. It would be interesting to examine the changes in

7 In a private communication, J. P. MeCullough has suggested that the nonlinearity in the liquid state is due to a contribution from short range order which decreases exponentially with temperature above the melting point. If this Higher temperature specific heat data can clarify this point. 
specific heat of polyethylene with lamellar thickness to see if the discrepancy could be resolved. It might also be useful to attempt to analyze the data in this paper in the manner reported recently by Wunderlich [8]. It is desirable to have more $n$ paraffin specific heat data for longer chain lengths and higher temperatures in order to increase the accuracy and temperature range of the predicted higher temperature solid and liquid thermodynamic values.

\section{References}

[1] B. Wunderlich, Motion in Polyethylene I, J. Chem. Phys. 3\%, 1203, (1962).

[2] E. F. Westrum, Jr., and J. P. McCullough, Physics and Chemistry of the Organic Solid State, Chapter 1, $I$, A. Weissberger et al., editors, Interscience Publishers (in press).

[3] M. Broadhurst, J. Research NBS 66A, 241 (1962).

[4] M. Broadhurst, J. Chem. Phys. 36, 2578 (1962).

[5] D. R. Douslin and H. M. Huffman, J. Am. Chem. Soc. 68, 1704 (1946).
[6] H. L. Finke, M. E. Gross, G. Waddington and H. M. Huffman, J. Am. Chem. Soc. \%6, 333 (1954).

[7] J. P. McCullough and J. F. Messerly, Bulletin 596 , Bureau of Mines, U.S. Department of the Interior, U.S. G.P.O. (1961).

[8] B. Wunderlich, Motion in Polyethylene II (to be published).

[9] E. Passaglia and H. G. Kevorkian, J. Appl. Polymer Sci. 7, 119 (1963).

[10] R. Chiang and P. J. Flory, J. Am. Chem. Soc. 83, 2857 (1961).

[11] F. S. Dainton, D. M. Evans, F. E. Hoare, and T. P. Melia, Polymer, 3, 277 (1962)

[12] B. Wunderlich and M. Dole, J. Polymer Sci. 24, 201 (1957).

[13] J. D. Hoffman, J. Chem. Phys. 29, 1192 (1958).

(Paper 67A3-210) 